\title{
The Influence of Temperament and Mothering on Attachment and Exploration: An Experimental Manipulation of Sensitive Responsiveness among Lower-Class Mothers with Irritable Infants
}

\author{
Dymphna C. van den Boom \\ University of Leiden
}

\begin{abstract}
VAN DEN BOOM, DYMPHNA C. The Influence of Temperament and Mothering on Attachment and Exploration: An Experimental Manipulation of Sensitive Responsiveness among Lower-Class Mothers with Irritable Infants. ChILd Development, 1994, 65, 1457-1477. 6-month-old infants selected on irritability shortly after birth and their mothers were randomly assigned to 2 intervention and 2 control groups to test the hypothesis that enhancing maternal sensitive responsiveness will improve quality of mother-infant interaction, infant exploration, and attachment. The intervention lasted 3 months and ended when the child was 9 months of age. When infants were 9 months of age, intervention group mothers were significantly more responsive, stimulating, visually attentive, and controlling of their infant's behavior than control group mothers. Intervention infants had higher scores than control infants on sociability, self-soothing, and exploration, and they cried less. Quality of exploration also improved, with intervention infants engaged in cognitively sophisticated kinds of exploration more than control infants. At 12 months of age, significantly more intervention group dyads were securely attached than control group dyads.
\end{abstract}

Over the last 15 years, researchers have demonstrated that insecurely attached infants function less well than their securely attached peers on a variety of tasks during their toddler, preschool, and beginning school years. Insecurely attached youngsters appear less effective in interpersonal relations (Londerville \& Main, 1981; Maslin \& Bates, 1982; Sroufe, 1983; Sroufe, Fox, \& Pancake, 1983; Thompson \& Lamb, 1983) and less successful in their efforts to master challenging tasks (Erickson \& Farber, 1983; Main, 1973; Matas, Arend, \& Sroufe, 1978) than their securely attached peers, and they show a high incidence of behavioral problems (Erickson, Sroufe, \& Egeland, 1985; Lewis, Feiring, McGuffog, \& Jaskir, 1984). Such evidence suggests that attachment theory and research are of clinical significance. Nonetheless, attachment theory has had surprisingly little direct impact on the design and the evaluation of clinical child care, despite the fact that groups of parents and babies who are at risk for developing anxious attachments have been identified. The present study is an intervention study conceptually linked to attachment theory.

According to attachment theory, differences in attachment as assessed in the Strange Situation are related experientially to differences in the sensitivity of caregiver's responses to infant's signals and communications during the infant's first year of life (Ainsworth, Blehar, Waters, \& Wall, 1978). Empirical support for the central role of sensitivity has been provided by several studies in which the 1-year-old infants of mothers rated as highly sensitive were significantly more likely to be securely attached than those of mothers rated as less sensitive (Bates, Maslin, \& Frankel, 1985; Belsky, Rovine, \& Taylor, 1984; Egeland \& Farber, 1982, 1984; Grossmann \& Grossmann, 1982; Isabella \& Belsky, 1991; Isabella, Belsky, \& von Eye, 1989; Smith \& Pederson, 1988). Although attachment classification describes the quality of the infant's relationship with

This research was supported by a Netherlands Organization for the Advancement of Pure Research grant (56-212) to the author. Thanks are due to Noortje Gerritsen, Gera Kofman, Yvonne Mathijsen, Daniëlle Mol, Ank Westerink, and Gerlach Zeegers for their help in data collection and scoring. The author would also like to thank Jay Belsky, Mary Rothbart, and the anonymous reviewers for their thoughtful suggestions. Reprint requests should be addressed to Dymphna C. van den Boom, Department of Developmental and Educational Psychology, University of Leiden, Wassenaarseweg 52, 2333 AK Leiden, The Netherlands.

[Child Development, 1994, 65, 1457-1477. (C) 1994 by the Society for Research in Child Development, Inc. All rights reserved. 0009-3920/94/6505-0006\$01.00] 


\section{Child Development}

a parent, situational factors as well as the characteristics of both the parent and the infant also contribute to the quality of this relationship (Belsky \& Isabella, 1988).

Recently, it has been hypothesized that temperamental differences in infants affect the development of infant-mother interactions and, thus, the mother-infant attachment relationship. In general, temperament is regarded as a constitutionally based predisposition that is stable across time and generalizable across situations (Buss \& Plomin, 1984; Rothbart \& Derryberry, 1981). The temperamental dimension of irritability, or a low threshold to expression of negative affect, has been shown to influence the quality of mother-infant interaction. Associations between infant irritability and maternal behavior have been investigated using different kinds of measures of irritability. Some studies used measures of infant irritability that are independent of caregiving behavior (Crockenberg \& Acredolo, 1983; Crockenberg \& Smith, 1982; Fish \& Crockenberg, 1981; Linn \& Horowitz, 1983; Osofsky, 1976; Osofsky \& Danzger, 1974; van den Boom, 1989), while others used parent report measures (Bates, Olson, Pettit, \& Bayles, 1982; Campbell, 1979; Caron \& Miller, 1981; Crockenberg, 1986; Kelly, 1976; Klein, 1984; Lee \& Bates, 1985; Milliones, 1978; Peters-Martin \& Wachs, 1984; Pettit \& Bates, 1984; Vaughn et al., 1992). The results of the studies using parent report measures are conflicting. Some studies report more responsive mothering with irritable babies while others report less involved contact. The reason for this inconsistency may be that parent report measures do not avoid confounding irritability with maternal caregiving behavior (Crockenberg, 1986). The majority of studies using observational measures of infant irritability seem to suggest that a heightened level of irritability is associated with less maternal involvement. This in turn may negatively influence the quality of attachment. In light of such findings, this intervention study was designed around children selected for being especially irritable as newborns as indexed by two separate Brazelton exams.

Current research also underscores the need to look beyond characteristics of the parent and infant in order to understand what transpires between them (Belsky \& Isabella, 1988). Thus, the question we now address is whether characteristics of the social context influence mothering behavior and the quality of attachment. Several stud- ies reported results indicating that a low level of maternal responsiveness is prevalent in lower-class families (Mey, 1992), resulting in an overrepresentation of anxious attachments (Koot, 1988). Because we wanted to be able to test the effect of temperament and of intervention, we preselected a sample that would be at risk for insecurity not only on a (presumed) temperamental basis but also on the quality of care that might be available to the infants. Groups were selected so that the incidence of stressful life events would be similar and thus an improvement in the intervention group could be attributed to the effectiveness of the intervention rather than to changes in external circumstances. Hence, in addition to selecting irritable infants, all infants came from lower-class families.

In this study, the intervention strategy was directed at promoting secure attachment by improving the mother's ability to monitor infant signals attentively, perceive infant signals accurately, and respond appropriately and contingently. More specifically, the concept of felt security (Ainsworth, 1973; Waters, 1981) was used as a point of departure for the intervention. Felt security refers to the emotional core of a relationship with a specific caregiver which is characterized by feeling safe and protected in the presence of that person and by feelings of longing and desire to restore proximity and contact when that person is absent. Recurrent experiences of feeling unprotected due to maternal insensitivity have a profound influence on the process of internalizing the role of the attachment figure as protector. When the working model of attachment incorporates salient features of maternal unprotectiveness, the child's ability for selfprotection is in turn jeopardized. Distortions in self-protecting mechanisms may then be observed in many areas of the child's behavior, particularly those that involve the need to negotiate a balance between the attachment system and the child's involvement in exploration (Lieberman \& Pawl, 1990). Thus, the intervention is geared toward ameliorating disorders of attachment by focusing on their roots in the mother-child interaction. Since the population under study was a basically well-functioning, lower socio-economic status sample with normal but irritable babies, our intervention used a skills-training format emphasizing specific behavioral goals within an overall framework of using the power of contingencies to influence interpersonal behavior. The inter- 
vention was implemented during naturally occurring mother-child interactions in the home, potentially the most direct way to affect behavior.

This report is unique in that it concerns a study designed to influence the critical maternal processes postulated to affect security to see not only whether the intervention influences sensitive responsiveness but also whether intervention and control subjects vary in rates of security. We hypothesized that mothers in the intervention group would be more sensitively responsive at the end of a 3-month intervention period (infant age 9 months) than mothers in the control group and that intervention infants would be more likely to be secure 3 months later (infant age 12 months) in the Strange Situation than control infants. And, given that attachment and exploration are supposed to be complementary behavioral systems-the attachment system aimed at promoting proximity to/contact with the mother and the exploratory system aimed at gaining information about the environment-we expected that intervention infants would engage in more cognitively sophisticated exploration after the intervention period than control infants.

\section{Method}

\section{SUBJECTS}

The data are based on 100 mother-child pairs observed at infant ages 6,9 , and 12 months for whom complete data were available on all measures used. At the time of the child's birth, 97 of the 100 families were intact; three mothers were single. Two fathers were unemployed. In all instances the mother was the primary caretaker. All infants were Caucasian, firstborn, and from low-SES families. Social class was assigned according to the social group division of the Netherlands Central Bureau of Statistics (1971). All infants were carried to term (between 38 and 42 weeks of gestation) and weighed more than 2,500 grams at birth. Pregnancies were uncomplicated, and deliveries did not involve mid- or high-forceps, caesarean section, or breech birth. Mothers did not receive more than routine medication during delivery. Apgar scores were at least 7 at $1 \mathrm{~min}$ and 8 at $5 \mathrm{~min}$.

The families were located through the birth register of the Department of Obstetrics and Gynecology of the Leiden University Hospital and through midwives in the Leiden area. The mothers ranged in age from 19 to 33 years. The infants were selected on irritability on the tenth and the fifteenth day after birth with the Neonatal Behavioral Assessment Scale (NBAS; Brazelton, 1973). ${ }^{1}$ The author administered the Brazelton exams during the course of the study. To assess degree of irritability, scores on the peak of excitement, rapidity of buildup, and irritability items were combined to form the neonatal irritability measure identified by Kaye (1978). These three items have been used by other researchers interested in infant irritability. (Crockenberg, 1981). Infants whose mean score from both exams on these three items was 6 or higher were considered irritable; those whose mean scores were below 6 were considered nonirritable. To find the predetermined number of 100 irritable infants, the NBAS had to be administered to 588 infants. Thus, $17 \%$ of infants from low-SES families proved to be irritable according to the criterion used in the present study. The final sample consisted of 47 girls and 53 boys.

\section{Overall Design}

Subjects were randomly assigned to the intervention and control groups, resulting in 50 dyads who received the intervention and 50 dyads who did not. In addition, all 100 dyads received two immediate posttreatment assessments (mother-infant interaction and infant exploration) and a delayed posttreatment assessment (attachment security).

A posttreatment-only control group design poses several problems. On the one hand, it remains unclear whether the groups were truly equivalent on critical variables before the intervention, which suggests that pretreatment evaluation is necessary. On the other hand, pretests may have an interaction effect with the actual intervention. To overcome these problems, half of the intervention and half of the control subjects received a pretreatment assessment and half did not, creating a factorial design: two treatment conditions (control and intervention) and two pretest conditions (pretest and no pretest). This four-group design (Solomon \& Lessac, 1968) enables assessment of pretreatment differences between the interven-

${ }^{1}$ The author was trained to administer the scale at the Child Development Unit of the Children's Hospital Medical Center in Boston by Dr. Brazelton and his group. 


\section{Child Development}

tion and control groups. It also enables assessment of the interaction of pretreatment testing with the intervention. In addition, the pretested control group was observed as often as the intervention groups were visited in order to control for the fact that getting attention alone would affect maternal behavior.

Thus, the sample consisted of 25 mother-infant pairs per group. The four research groups do not differ in demographic characteristics (see Table 1).

Numerous tests were performed to assess the effect of pretreatment data collection on the effect of the intervention. Virtually no influence was exerted, at least none that substantially changed the overall effects of the intervention found when pretreatment status was not taken into consideration. Because the reporting of the results when effects of intervention are tested in concert with pretreatment status is unwieldy and adds little of substance, all findings will be reported without regard to pretreatment status, except for the issue of pretreatment group differences. ${ }^{2}$

\section{Procedures and Data Reduction}

The reporting of procedures is divided into three sections, one dealing with pretreatment measurement, another with posttreatment evaluation, and the last with the intervention.

\section{Pretreatment Assessment}

Two sets of measurements were taken, one pertaining to the quality of motherinfant interaction, the other to the quality of infant exploration. In addition, mothers filled out an inventory of life events. Fifty of the 100 dyads participated in this phase of the study.

\section{Mother-Infant Interaction}

The 6-month assessment consisted of two home visits. During each visit, $40 \mathrm{~min}$ of mother-infant interaction in routine family contexts (feeding, bath, play, etc.) was observed. One visit was scheduled in the morning, the other in the afternoon. Observations were of interactions between mother and infant. When, at times, the mother decided not to interact, observations were made out of the interactional context, with focus on the child. The interactions were not videotaped.

Coding of interaction.-All four observers were trained intensively over a period lasting at least 3 months and were blind to group assignment of the dyads. While the mothers were going about their daily routines, conversation with the observer was not encouraged, and the observers were trained to minimize the potential intrusiveness of their presence. Mother and child behaviors were recorded at 6-sec intervals identified by a beep emanating from a timer and communicated to the observer through an inconspicuous earplug. During the course of the study, formal reliability assessments were conducted during in-home observations by having two observers observe the same interaction and code it independently. Interobserver agreement was computed using Cohen's kappa on 25\% of the visits per month for all combinations of observer pairs. Reliability coefficients for the composite variable sets used in the analyses are included in Table 2.

Coding categories for maternal interactive behavior.-Observational categories for the mother consisted of behavior-based measures of those dimensions of maternal behavior that have been found to be related to later quality of attachment, that is, affective, attentive, supportive, soothing, and stimulation behaviors. In addition, the coded observational data were used to define a more conceptually complex measure of responsiveness: operational measures of a mother's responsiveness were computed based on an analysis of contingencies between observed infant and maternal behaviors. The infant behaviors included in the observational system might be expected to elicit maternal responses (e.g., crying, vocalizing). For each of these infant behaviors, a set of maternal behaviors was selected which would indicate an "appropriate" response to the specific infant behavior. For example, for infant vocalizes to mother, appropriate responses from the mother were: comes to infant, looks at infant, or verbalizes to infant. Each recorded occurrence of each of the infant behaviors was considered, its consequents within the same or the next 6-sec period were examined, and each maternal behavior was given a responsiveness code. Responsive behaviors were circled on the coding sheet; unresponsive behaviors were not.

2 More details on analyses examining the effect of pretreatment data collection in interaction with the intervention are available from the author upon request. 


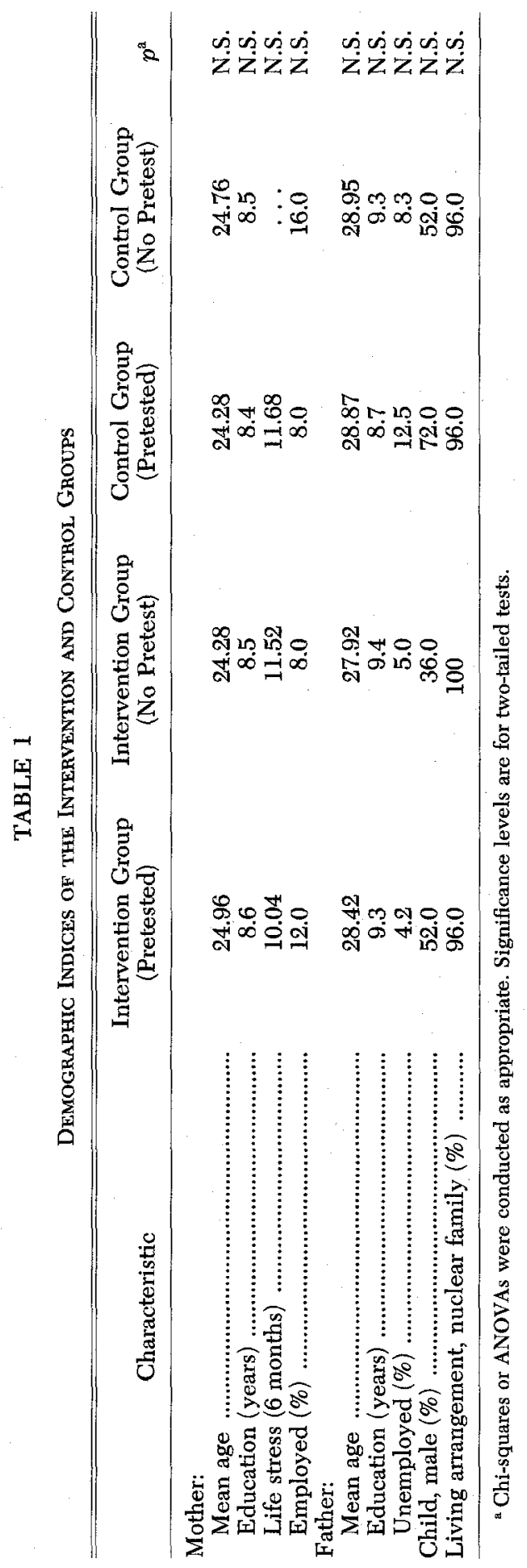


TABLE 2

Observation Code Categony Clusters With KapPas for Each Cluster

\begin{tabular}{|c|c|}
\hline Code Cluster & Kappa \\
\hline \multicolumn{2}{|l|}{ Maternal interactive behavior: } \\
\hline 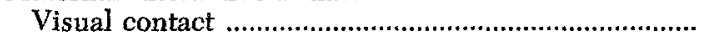 & .75 \\
\hline Physical contact & .74 \\
\hline Stimulation & .76 \\
\hline Effective stimulation & .74 \\
\hline 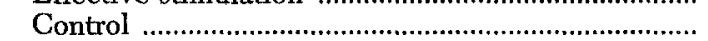 & .80 \\
\hline Soothing ....................... & .79 \\
\hline 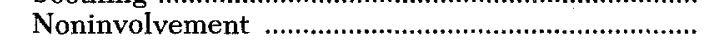 & .81 \\
\hline Instruction & .77 \\
\hline 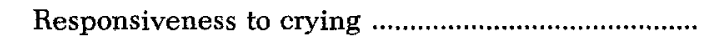 & .79 \\
\hline Responsiveness to positive signals .............................. & .78 \\
\hline Ignoring of crying & .76 \\
\hline \multicolumn{2}{|l|}{ Infant interactive behavior: } \\
\hline Distant contact & .64 \\
\hline Positive social behavior & .72 \\
\hline Negative emotionality & .76 \\
\hline Exploration & .72 \\
\hline Mobility ......... & .79 \\
\hline 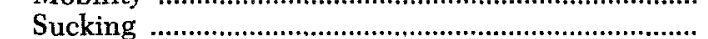 & .76 \\
\hline Environmental interest & .75 \\
\hline \multicolumn{2}{|l|}{ Infant exploratory behavior: } \\
\hline 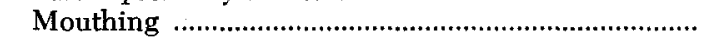 & .67 \\
\hline Undifferentiated manipulation .................................. & .71 \\
\hline Vigorous exploration & .70 \\
\hline Relational exploration & .77 \\
\hline Specific exploration & .80 \\
\hline Simple exploration & .75 \\
\hline
\end{tabular}

Two scores of maternal responsiveness were calculated based upon the proportion of infant behaviors to which the mother responded: responsiveness to the infant's distress and responsiveness to the infant's social signals. It was deemed important to calculate two separate responsiveness scores because the absolute value of the base rate of infant distress behavior is relatively high in irritable infants. This puts special demands on responses from the mother and also means that perception of contingency becomes difficult for the infant (Watson, 1979) because the mother is likely to respond to infant distress with behaviors that she is likely to use in response to other infant signals as well. For instance, if the mother's base rate of vocalizing is quite high and she also uses vocalizing in response to her infant's distress, it will be difficult for the infant to detect the contingency between crying and vocalizing. If, on the other hand, the mother resorts to effective soothing strategies in response to distress, the infant's perception of contingency will be facilitated, since it is unlikely that the mother will use soothing behaviors in response to other in- fant signals. The responsiveness scores reflect the inherent interdependence of interactors by combining the behaviors of the two participants into a dyadic score that reflects the functioning of the pair.

Attachment researchers have found that ignoring infant crying will lead to increased crying at later ages (Bell \& Ainsworth, 1972). To verify this conclusion in our sample of irritable infants, a score was computed for ignoring of infant crying by mothers. This score was the percentage of time as a proportion of infant fussing and crying that these signals were completely ignored.

To compute the proportional measures of responsiveness and ignoring of infant crying, the number of 6-sec periods in which each behavior unit or specified combination of behavior units occurred was tallied, a behavior recorded more than once in a 6-sec period being counted only once. Calculations were made for fussing/crying, positive behaviors, and the maternal responsiveness codes. These frequencies were then converted to proportions in order to provide comparable scores for subjects whose 
amount of fussing/crying or positive signaling behavior differed in length. Data reduction was performed on the two proportional scores of responsiveness, the proportional score of ignoring of infant crying, and the behavior-based measures of maternal sensitive responsiveness from the observational code.

Data reduction of maternal interactive categories.-The wealth of observational data gathered was reduced to improve the case-to-variable ratio. Composite variables were created on empirical grounds (i.e., intercorrelations between behavioral categories). Variables that, on inspection of means and standard deviations, did not occur with sufficient frequency at 6 months were summed on the basis of their intercorrelations at 9 months. Because the infants were studied during a period of rapid developmental change, some variables increased considerably over the age range investigated (e.g., instruction). Since these variables were observed with high frequency at 9 months, it was not deemed appropriate to eliminate these behaviors from subsequent analyses on the basis of their frequency at 6 months. Maternal verbal and physical instruction were summed because of their low individual frequency of occurrence at 6 months. For the same reason, the frequencies of the soothing behaviors were summed together. Correlations among the discrete variables included in the composites were all high ( $\geq .50)$. Maternal neutral and positive expression were significantly related and were less likely to occur when the mother was attending to her child's needs. By summing the frequencies of these three categories, visual contact was created. High rates of physical stimulation were associated with high rates of bodily contact. The sum of their frequencies constitutes physical contact. Mothers who offered their infants objects to play with were also high in vocalizing, and the frequencies of these two behaviors were summed to obtain stimulation. Positive vocalization, stimulate to play, effective physical stimulation, and affectionate contact were all significantly related. These frequencies were summed to make $e f$ fective stimulation. High rates of verbal disapproval were associated with high rates of physical restraint. Control was created by summing the frequencies of these two behaviors. Maternal noninvolvement, soothing, and instruction were not significantly related to any of the other behavioral categories and were retained separately. Together with the two responsiveness scores and ignoring of infant crying, these eight maternal composite variable sets were entered into further analyses (see Table 2).

Coding categories for infant interactive behavior.-The observational system for the infant was focused entirely on attachment behaviors that develop during the first year of life (Ainsworth, 1973) and included orienting (look, look at), signaling (positive vocalization, other vocalizations, smile, fuss, cry, suck), and proximity- and contactpromoting behaviors (positive and negative physical expression, locomote). Exploratory behavior (object manipulation) was also included because of our interest in the attachment-exploration balance.

Data reduction of infant interactive categories.-Data reduction of infant behaviors proceeded according to the same procedure as for maternal categories. Because of their low frequency of occurrence at 6 months, dropping toys and manipulation, positive vocalization and contact maintenance, and crying and contact resistance were summed. For the most part, correlations between specific infant behaviors included in the composites were clear-cut $(>.50)$. Looking and vocalizing were significantly related, and their summed frequencies constituted distant contact. Positive social behavior was created by summing the frequencies of positive vocalization and smiling, which were signifcantly related. High rates of fussing were associated with high rates of crying, and by summing together the frequencies of these individual behaviors negative emotionality was created. Picking up toys and manipulation were significantly related, and the sum of their frequencies captured exploration. Locomoting, sucking, and looking at persons, objects, or events had much lower correlations with the other behavioral categories and were, therefore, retained separately as mobility, sucking, and environmental interest. This analysis resulted in seven composite variable sets for infant interactive behavior (see Table 2).

\section{Infant Exploration}

Quality of exploration was measured in a free play situation. The validity of such an approach is suggested by previous research showing that infant free play behavior that draws upon both cognitive and motivational skills is sensitive to ontogenetic change (Belsky, Garduque, \& Hrncir, 1984; Sorce \& Emde, 1981) and that the quality of such ac- 


\section{Child Development}

tivity can be influenced by the infant's early environment in a way predicted by contemporary attachment theory (Belsky, Goode, \& Most, 1980). Therefore, a free play task was administered during the first home visit prior to observation of mother-infant interaction. During administration, the infant sat on his or her mother's lap at a feeding table. The mother was instructed to refrain from interacting with or encouraging the infant while the infant played with the toys. At the start of each session, a warm-up toy (a small plastic booklet with attractive pictures) was presented to the infant for $1 \mathrm{~min}$ in order to attract the infant's attention to the task. Following the warm-up period, the infant was presented with three sets of toys for 5 min each. The toys were presented in a fixed order.

Coding of infant exploration.-All observers were extensively trained to reliability and blind to group assignment of the dyads. Every $3 \mathrm{sec}$, an exploratory behavior and the toy with which it was performed were registered. Exploratory behaviors were coded in vivo. Interobserver agreement was computed as for the interactive categories using Cohen's kappa on $75 \%$ of the visits for all combinations of observer pairs. Agreement coefficients are included in Table 2.

Coding categories for infant exploration.-The observational system consisted of looking, undifferentiated exploratory behaviors (e.g., mouthing, simple manipulation, rotation), and functional behaviors, that is, behaviors that fit the specific features of the toys. In addition to the categories included in the observational system, we employed summary and derived measures that represented indices of tempo, attention span, and level of exploration.

Several investigators have noted vast individual differences in tempo of exploration-the extent to which the infant moves from one toy to the next as opposed to maintaining sustained contact with a single object (Kagan, 1971; Maccoby \& Feldman, 1972; McCall, 1974). Wenckstern, Weizmann, and Leenaars (1984), who studied the relation between temperament and tempo of play, found that rapid-tempo infants are more intense, more negative in mood, and less sensitive to environmental stimulation. Thus, to control for the possibility that the irritable infants, who are intense and negative in mood, might be less sensitive to free play than nonirritable infants, we included a measure on behavioral tempo. Perseverance time (the index of tempo) was computed the following way. First, we computed the total amount of time spent in physical contact with a toy (total contact time) and the total number of times an infant made contact with a different toy (act changes). Multiple contacts with the same toy were counted as act changes when the contacts were separated by intervals of $3 \mathrm{sec}$ or more. Finally, perseverance times, derived separately for each infant, were computed by dividing the contact time scores by the number of act changes.

Although Wenckstern et al. (1984) did not find a relation between tempo and the ability to sustain attention, they suspect that such a relation might be revealed if attentional indices that are more subtle than the relatively gross measures of overall attention captured by temperament questionnaires were used. In exploration sessions where several toys are offered at the same time, Power, Chapieski, and McGrath (1985) found that infants become distracted by one toy while they are playing with another and that they spend time sorting through the objects before finding one that eventually catches their attention. Following Power et al. (1985), two measures of attention span were computed: total amount of time spent exploring toys during the entire session and mean length in seconds of the two longest periods of uninterrupted object involvement. Attention span was defined as the tendency to focus attention on an object or objects for prolonged periods, especially once suitable object(s) for extended exploration had been found. The second measure of attention span was chosen instead of the average length of object involvement calculated over all instances because the latter would include, inappropriately, the brief periods of object involvement attendant on the infant's sorting behavior.

Level of exploration, that is, the highest level of exploration observed, was identified on a 12-step sequence-of-play scale developed by Belsky and Most (1981). Belsky, Garduque, and Hrncir (1984) showed that the highest level of play spontaneously generated during free play is related to the quality of attachment and, possibly, to maternal sensitive responsiveness. It might be expected, therefore, that the intervention would affect the highest level of play. Thus, the four summary and derived measures included in the analyses, in addition to the six composite variable sets derived from the observational system (see below), were: perse- 
verance time, two measures of attention span (total amount of time exploring toys [I]; mean length of the two longest periods of uninterrupted object involvement [II]), and highest level of exploration.

Data reduction of infant exploratory categories.-For infant exploration, the following six composite variable sets were created $(r \mathrm{~s}>.50)$. Other mouthing was negatively related to both active mouthing and alternate. Their summed frequencies constitute mouthing. A significant correlation was obtained between detailed manipulation and rotating. The frequencies of these behaviors were summed together to create undifferentiated manipulation. Vigorous manipulation and throwing with visual guidance were significantly related. The summed frequencies of these behaviors constitute vigorous exploration. High rates of simple relational behavior were associated with high rates of grouping. Their summed frequencies make up relational exploration. Specific exploration consisted of the summed frequencies of functional and functional-relational exploration, which were significantly related. Since simple manipulation was not highly correlated with any of the other exploratory categories, it was retained separately. Together with perseverance time, the two measures of attention span, and level of exploration, these six exploratory composites constituted the basis for further analyses (see Table 2).

\section{Factor Analyses}

Because several of the composite variable sets had skewed distributions, data were logarithmically transformed to promote multivariate normality. Complete data were available for all subjects. To obtain the factor scores to test for differences between the intervention and control groups, principal components analyses (VARIMAX rotation) had to be performed on both the total sample and subsets of the data, that is, on data from the two pretested groups $(N=50)$ and the total sample $(N=100)$. The solutions obtained were very similar. In each solution, four components were extracted with the same variables loading on the components. Only slight differences emerged in the order in which variables loaded on the factors. To avoid repetitious presentation of results, only the solution obtained for the two pretested groups is presented here.

The 11 maternal interactive composite variable sets were subjected to a principal components analysis. Four components ac- counted for $80 \%$ of the variance: responsiveness, stimulation, visual attentiveness, and control. The seven infant interactive composite variable sets yielded three principal components accounting for $71 \%$ of the variance: social behavior, self-soothing, and exploration. A principal components analysis of the 10 infant exploratory composite variable sets extracted four components accounting for $80 \%$ of the variance: sophisticated exploration, tempo of exploration, nonspecific manipulation, and mouthing. Table 3 presents an overview of the three principal components solutions.

\section{Questionnaires}

During the home visits, an inventory of life events (23 items) adapted from the list reported by Egeland, Breitenbucher, Dodds, Pastor, and Rosenberg (1979) was administered to the mothers to assess stressful circumstances. Items covered areas such as financial problems and family discord. Each item checked was assigned a weight between 1 and 5 , depending on the degree of disruption involved and readjustment required. The authors report a mean score of 4.0 for a normative sample and a mean score of 8.0 for a high-risk sample. A score of 11 or higher places the family in the upper $20 \%$ for incidence of stressful events. Stressful life events experienced by subjects in the present sample included financial problems, emotional problems, marital discord, and serious illness. The four groups of subjects do not differ in reported life stress (see Table 1).

\section{Posttreatment Assessment}

\section{Immediate Posttreatment}

The 9-month assessment again consisted of two home visits. As during the pretreatment assessment, mother-infant interaction was observed for $80 \mathrm{~min}$, quality of exploration during free play was evaluated, and the inventory of life events was administered. Pre- and posttreatment observations for the same family were performed by different observers who were blind to treatment condition.

\section{Delayed Posttreatment: Attachment}

Each dyad was videotaped in the Ainsworth and Wittig (1969) Strange Situation when infants were 12 months of age. Classifications were assigned according to the secure (B), insecure avoidant (A), insecure resistant (C) (Ainsworth et al., 1978), and insecure disorganized/disoriented (D) groups (Main \& Solomon, 1990). 


\section{Child Development}

\section{TABLE 3}

Results of Three Principal Components Analyses: (1) Maternal Interactive,

(2) INFANT INTERACTIVE, AND (3) INFANT EXPLORATORY COMPOSITES

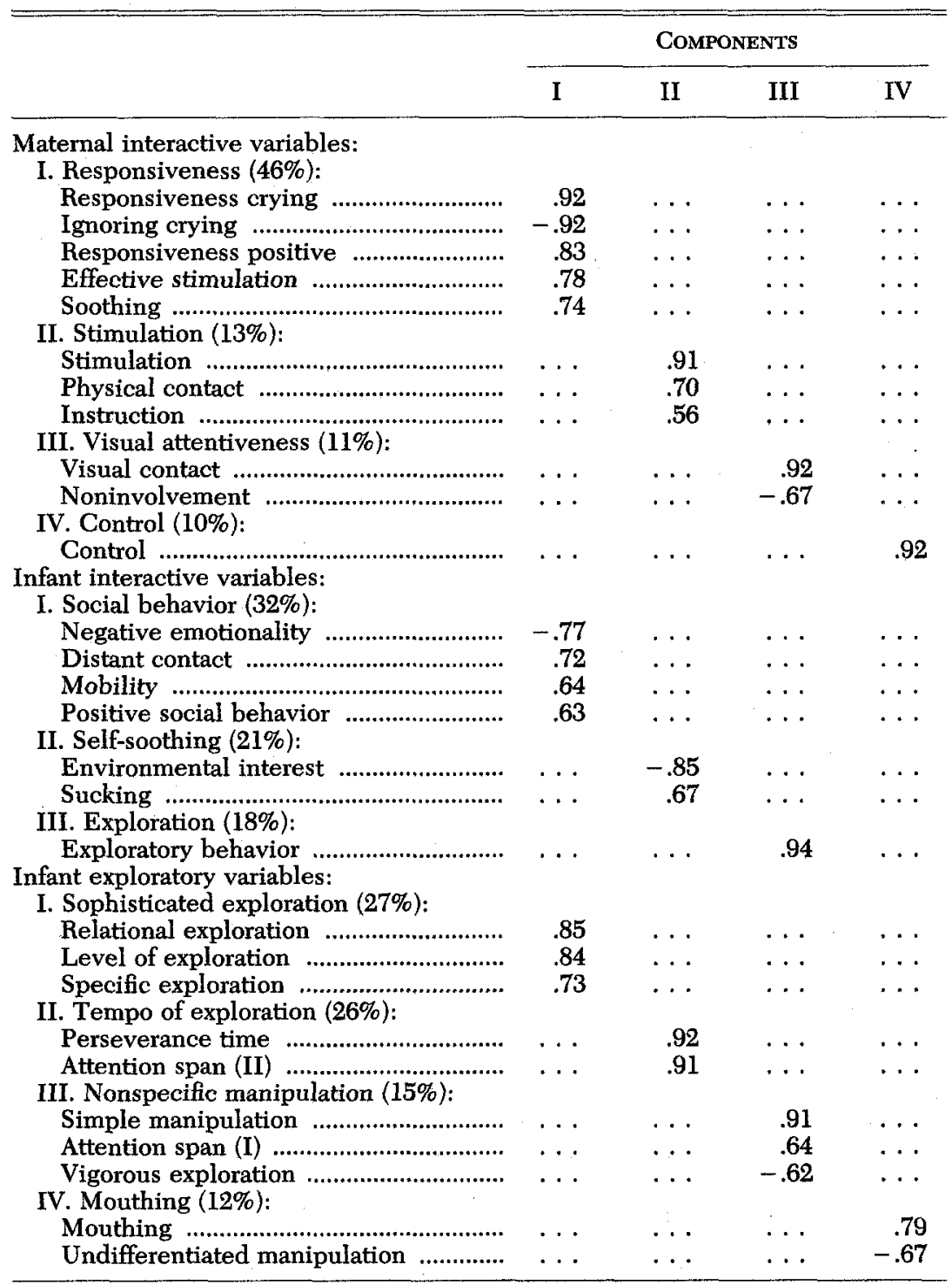

Videotapes were independently coded by two observers trained by the author. ${ }^{3}$ Training was done on pilot data from 40 mother-infant pairs. Coders had to achieve at least $90 \%$ reliability on these tapes. Coders were blind to all other data on the families, including irritability or intervention status. Interrater reliability was conducted on all tapes; Cohen's kappa of interrater agreement was .94 .

\section{Intervention}

The intervention began 3 weeks after pretreatment assessments. Mothers were asked if they wished to participate in the firstborn program being offered for first-time

${ }^{3}$ The author was trained to reliability at the Institute of Child Development in Minneapolis by Dr. Sroufe and his group. 
mothers. The program was described as an opportunity for mothers to talk with staff about their concerns regarding child rearing. Mothers were not told about their infant's inritability classification, since it is not feasible to tell a mother of a healthy, full-term firstborn that her infant is considered to be at risk for subsequent emotional difficulty. Such labeling might even set in motion a self-fulfilling prophecy; some evidence exists that children labeled as atypical may be treated differently by caretakers (Aber \& Baker, 1990). Three intervention sessions were scheduled for the dyads of the intervention groups while the infants were between 6 and 9 months of age (i.e., one session every 3 weeks). During the entire 3-month intervention period, the author carried out the interventions. Thus each dyad had one and the same intervenor. All visits took place in the home and lasted about 2 hours. The intervention was implemented during everyday interactions.

The intervention was focused on enhoncing maternal sensitive responsiveness. Toward this end, we assisted mothers in adjusting their behaviors to the infant's unique cues, and in doing so we elaborated on what we had learned from the results of an observational study. In the observation study, irritable infants were found to be less attentive and less responsive to their mothers and they seemed to "enjoy" their interactions with their mothers less than nonirritable infants: their smiles and contented vocalizations were less frequent and their fusses and cries were more frequent than those of normal infants. Mothers responded with increasing inactivity or passivity to their irritable infants. Hence, the infant's crying seems to focus events in an unhealthy way. As soon as the infant stops crying, interaction is reduced to a minimum to prevent the infant from starting to cry again (van den Boom, 1988). Although infants were selected on irritability shortly after birth, the intervention started when infants were approximately 6 months of age. The results of the observational study showed that having an irritable infant resulted in a negative cycle of interaction becoming apparent from about the fifth month of life, despite the fact that the actual amount of fussing/crying decreased with age (van den Boom, 1991). Intervention was guided by the four stages of the response process: (a) perceiving an infant signal, $(b)$ interpreting the signal correctly, (c) selecting an appropriate response, and $(d)$ implementing the response effectively. Insensitiv- ity could be the result of a deficiency in any of these stages of the reception-response sequence.

To influence accurate signal perception and interpretation by mothers, we began by affecting maternal attentive behavior. We encouraged mothers to imitate their infant's behaviors, to repeat their own verbal expressions, and to maintain silence while their infant's gaze was averted. These maternal behaviors have been shown to be effective in one-time laboratory manipulations (Field, 1982). Attentiveness to infant signals is critical for a sensitive maternal response to occur. The accompanying infant gaze behavior indicates whether the infant is being attentive or inattentive, and gaze aversion by the infant is an often-reported manifestation of disturbed interactions (Stern, 1971). Thus, infant gaze behavior provides feedback to the mother on whether she is accurately interpreting her infant's signals. In addition, interventions focused on maternal attentiveness have been shown to have the effect of simplifying and slowing down maternal interactive behavior, presumed to occur because of the greater attentiveness of the mother to alterations in her infant's behavior. This was also deemed important because it has been shown that irritable infants are very active, that is, their signaling behavior is high paced (van den Boom, 1991).

Interventions to influence the last two stages of the response sequence were intended to introduce variety and complexity in the mother's behaviors toward both negative and positive infant signals. Instances of fussing or crying served as targets for behavior change in sensitive responsiveness to negative infant signals. If the infant started to cry, some mothers spontaneously soothed them, and feedback was provided on the effectiveness of the soothing technique selected. If soothing did not occur, mothers were asked to soothe their infants, and the importance of soothing a crying infant was highlighted. Individualization was very important since some babies like close physical contact while others do not. Therefore, the mother was offered a number of alternative ways for dealing with the situation to arrive at an optimal meshing of behavior of the two interactive partners.

For mothers with irritable babies, it is also important to show that interactions can be positive and rewarding since these mothers are inclined to focus their interactive behavior on negative signals and to ignore 


\section{Child Development}

positive ones (van den Boom, 1991). Techniques used here included asking the mother to play with toys and play infant games, which typically served to increase the activity levels of the mothers during playful interactions. Here, too, attention was devoted to getting an optimal attunement of maternal behavior with infant signals.

Careful consideration in tailoring individual interaction intervention techniques proved to be very important. While the majority of mothers of irritable babies were extremely active once they initiated interaction with their infants, there were some mothers in which activity was typically low. Clearly, interventions for simplifying and slowing down the activity of these mothers would have been inappropriate and ineffective. Hence, the intervention aimed at reciprocal reading and responding to cues, which can have long-range favorable results because mothers will have gained skill in observing their infants, in understanding the importance of responding to both positive and negative infant signals, and in learning to anticipate changes in infant behavior and needs as a part of development. Our intervention was not a psychotherapeutic intervention, but a mothering/skill-based one.

After each intervention session, maternal and infant behaviors were observed with the observational system used for pretreatment observations. These observational data were used to evaluate the attainment (or nonattainment) of behavioral goals, to determine whether changes occurred, and to identify the focus of the next intervention session.

\section{Results}

The reporting of results, along with preliminary findings pertaining to the pretreatment comparison of the intervention and control groups, is divided into three sections: the first deals with preliminary analyses to establish the initial equality of means of the groups, the second with immediate posttreatment effects, and the last with delayed posttreatment effects.

The identified patterns (factor scores) were submitted to (repeated-measures) MANOVAs to test for differences between the intervention and control groups on maternal and infant interactive behavior and on infantile exploration behavior.

\section{Preliminary ANalyses}

To establish the initial equality of means of the groups, preliminary ANOVAs were applied to the pretreatment observations of maternal interactive behavior. No significant differences were found on any of the variable sets, with all $F$ values $(1,48)<$ $3.90, p \mathrm{~s}>.05$, except for effective stimulation on which the intervention mothers had lower rates $(M=1.46, \mathrm{SD}=1.05)$ than the control mothers $(M=3.82, \mathrm{SD}=.96), F(1$, $48)=81.49, p<.001$.

Preliminary ANOVAs applied to the pretreatment infant interaction rates did not differ significantly on five of the seven variable sets among the intervention and control conditions, with all $F_{\text {s }}(1,48)<3.00$, ps $>$ .05. Control group infants scored higher on positive social behavior $(M=2.65, \mathrm{SD}=$ $.73), F(1,48)=57.89, p<.001$, and mobility $(M=3.34, \mathrm{SD}=1.47), F(1,48)=50.76, p$ $<.001$, than intervention infants $(M=1.28$ and $1.29, S D=.83$ and 1.08 , respectively).

At the time of the pretreatment observations, infant exploratory behavior did not differ significantly on eight of the 10 variable sets among intervention and control conditions, with all $F$ values $\langle 3.25, p s\rangle .10$. Intervention infants showed more simple manipulation $(M=5.23, \mathrm{SD}=.16), F(1,48)=$ $12.94, p<.001$, and less vigorous exploration $(M=2.20, \mathrm{SD}=1.08), F(1,48)=$ $14.19, p<.01$, when compared to the control infants $(M=4.91$ and $2.80, \mathrm{SD}=.41$ and 1.07 , respectively).

No sex differences were obtained in separate analyses centered on the pretreatment variable. All data, therefore, will be reported for the sexes combined.

\section{Immediate Posttreatment Effects}

At 9 months of age, effects of the intervention were estimated on the quality of interactive behavior. Maternal and infant interactive behavior were analyzed separately to document changes in each partner's behavior. Effects of the intervention were also examined for infant exploratory behavior. Finally, changes in reported life stress were analyzed over the two points of measurement (6 months and 9 months infant age).

\section{Effect of Intervention on Maternal \\ Interactive Behavior}

To assess the effectiveness of the intervention a 2 (pretest: yes vs. no) $\times 2$ (intervention vs. control) MANOVA was carried out on the four maternal components: responsiveness, stimulation, visual attentiveness, and control. With the use of Wilks's criterion, the combined dependent variables 
were significantly affected by intervention, $F(4,93)=74.55, p<.01$, and by the interaction between pretest and intervention, $F(4$, $93)=2.64, p<.05$. There was no significant main effect of pretest. Univariate tests indicated that intervention mothers were significantly more responsive, $F(1,96)=$ $176.75, p<.001$, more stimulating, $F(1,96)$ $=35.56, p<.001$, more visually attentive, $F(1,96)=68.74, p<.001$, and more controlling of their infant's behavior, $F(1,96)=$ $26.23, p<.001$, compared to the control mothers. The mean factor scores for the intervention mothers were $4.32(\mathrm{SD}=1.71)$, $1.57(\mathrm{SD}=1.18), 1.04(\mathrm{SD}=.79)$, and 1.24 $(\mathrm{SD}=.87)$; control group mothers, on the other hand, had mean factor scores of -1.84 $(\mathrm{SD}=2.48),-.74(\mathrm{SD}=2.45),-.52(\mathrm{SD}$ $=1.04)$, and $.15(\mathrm{SD}=1.22)$. The interaction effect for intervention $\times$ pretest was significant only for visual attentiveness, $F(1$, $96)=4.77, p<.05$. Post hoc comparisons indicated that the pretested control group had significantly lower mean factor scores on visual attentiveness $(M=-.96, \mathrm{SD}=.78)$ than did the control group that was not pretested $(M=-.09$, SD $=1.31)$. No significant differences were found between the two intervention groups.

A MANOVA for repeated measures was performed on mothers' behaviors in the intervention and control group that received a pretest at 6 months of age. The withinsubject factor was time ( 6 vs. 9 months). This analysis showed multivariate main effects of intervention, $F(4,45)=9.09, p<.001$, and time, $F(4,45)=66.24, p<.001$, which were qualified by an interaction of intervention $x$ time, $F(4,45)=43.73, p<.001$. The univariate tests showed that the interaction effects were significant for all maternal components, that is, for responsiveness, $F(1,48)=$ $122.19, p<.001$, stimulation, $F(1,48)=$ $46.49, p<.001$, visual attentiveness, $F(1,48)$ $=38.90, p<.01$, and control, $F(1,48)=$ $41.46, p<.001$. In the intervention group, rates of maternal responsiveness ( $M_{6 \text { months }}=$ $-3.53, \mathrm{SD}_{6 \text { months }}=1.75 ; M_{9 \text { months }}=4.18$, $\mathrm{SD}_{9}$ months $\left.=2.39\right)$, stimulation ( $M_{6}$ months $=$ $-1.19, \mathrm{SD}_{6}$ months $=1.6 ; M_{9}$ months $=1.98$, $\mathrm{SD}_{9}$ months $=1.38$, and visual attentiveness $\left(M_{6 \text { months }}=-.35, \mathrm{SD}_{6 \text { months }}=1.12 ; M_{9 \text { months }}\right.$ $=1.01, \mathrm{SD}_{9 \text { months }}=.84$ ) increase over the two time points, these behaviors decreased slightly in mothers from the control group $\left(M_{6 \text { months }}=-.53,-10\right.$, and $-.47, \mathrm{SD}_{6 \text { months }}$ $=2.27,1.66$, and $.93 ; M_{9}$ months $=-1.62$, -.64 , and $-.96, \mathrm{SD}_{9 \text { months }}=2.83,2.36$, and .78 , respectively). Maternal control in- creased in both groups between 6 and 9 months of age, but the increase was larger in mothers from the intervention group $\left(M_{6 \text { months }}=-1.72, \mathrm{SD}_{6 \text { months }}=.85 ; M_{9 \text { months }}\right.$ $=1.49, \mathrm{SD}_{9}$ months $\left.=.76\right)$ compared to the control group mothers $\left(M_{6}\right.$ months $=-.84$, $\mathrm{SD}_{6 \text { months }}=.78 ; M_{9 \text { months }}=.17, \mathrm{SD}_{9 \text { months }}$ $=1.13$ ).

In sum, mothers who participated in the intervention did differ in meaningful ways from the control group mothers, and the differences were rooted in their responsive and stimulating orientation toward their infants.

\section{Effect of Intervention on Infant \\ Interactive Behavior}

A 2 (pretest: yes vs. no) $\times 2$ (intervention vs. control) MANOVA was used to assess differences on the infant components by intervention and pretest. Significant main effects of intervention and pretest were found using Wilks's lambda test of significance, $F(3,94)=56.55, p<.001, F(3,94)=10.60$, $p<.001$, respectively. There was no significant intervention $\times$ pretest interaction. Univariate tests indicated that infants in the intervention groups were significantly more sociable $(M=1.35, \mathrm{SD}=.92), F(1,96)=$ $31.73, p<.001$, more self-soothing $(M=.82$, $\mathrm{SD}=.71), F(1,96)=29.54, p<.001$, and explored more $(M=3.43, \mathrm{SD}=.91), F(1$, $96)=94.34, p<.001$, when compared to the control group infants $(M=.22,-.04$, and $-.17, \mathrm{SD}=1.07, .86$, and 1.01 , respectively). The effect for pretest was significant only for social behavior, $F(1,96)=13.45, p$ $<.001$, and self-soothing behavior, $F(1,96)$ $=10.85, p<.001$, with pretested intervention infants being more sociable $(M=1.88$, $\mathrm{SD}=.87)$ and more self-soothing $(M=1.13$, $\mathrm{SD}=.73)$ compared to the pretested control group infants $(M=.43$ and $.17, \mathrm{SD}=.96$ and .91 , respectively).

The entire population of the present study consisted of irritable infants. Irritable infants have been shown to fuss and cry more and to exhibit fewer positive social behaviors than nonirritable infants (van den Boom, 1988). Interest in these specific behaviors led to examination of changes from pretreatment to posttreatment for the variable sets positive social behavior and negative emotionality. ANOVAs yielded significant differences for intervention and control infants on each of these variable sets. These differences indicate that intervention infants displayed more positive social behavior directed to the mother $(M=4.72, \mathrm{SD}=.36)$, $F(1,96)=139.78, p<.001$, and showed less 


\section{Child Development}

negative emotionality during interactions ( $M$ $=2.10, \mathrm{SD}=1.20), F(1,96)=44.11, p<$ .001 , compared to control infants $(M=2.98$ and $3.39, \mathrm{SD}=1.01$ and 1.14 , respectively). For each of these variable sets, we found a main effect for pretest condition, with an $F$ value for positive social behavior of $F(1,96)$ $=5.72, p<.025$, and for negative emotionality of $F(1,96)=9.07, p<.01$. The interaction between intervention $\times$ pretest was also significant for positive social behavior, $F(1,96)=8.79, p<.01$, and negative emotionality, $F(1,96)=5.19, p=.025$. Contrary to our expectations, post hoc comparisons revealed that the control group that did not receive a pretest displayed higher mean factor scores on positive social behaviors ( $M=$ $3.33, \mathrm{SD}=1.04$ ) than the pretested control group $(M=2.62, \mathrm{SD}=.85)$. No differences emerged between the pretested and nopretest intervention groups. On negative emotionality, infants in the intervention group that did not receive a pretest scored higher $(M=2.68, \mathrm{SD}=1.09)$ than infants in the intervention group that did receive a pretest $(M=1.47, \mathrm{SD}=1.01)$. In this instance, no differences emerged between infants in the pretested and no-pretest control group.

A repeated-measures MANOVA on the infant components of the pretested intervention and control group yielded a significant multivariate main effect of intervention, $F(3$, $46)=9.22, p<.001$, and time, $F(3,46)=$ $134.31, p<.001$. The multivariate effect of the intervention $\times$ time interaction, $F(3,46)$ $=62.73, p<.001$, indicated the following differences between the intervention and control group. Univariate tests showed that the interaction effect was significant for social behavior, $F(1,48)=67.06, p<.001$, self-soothing, $F(1,48)=51.49, p>.001$, and exploration, $F(1,48)=36.53, p<.001$. Infant social behavior and exploration increased in both groups between the two points of measurement ( 6 and 9 months of age). In the intervention group, both behavioral components increased at a higher rate $\left(M_{6 \text { months }}=-2.81\right.$ and $-1.67, \mathrm{SD}_{6 \text { months }}=$ 1.56 and $1.31 ; M_{9}$ months $=1.88$ and 1.98 , $\mathrm{SD}_{9 \text { months }}=.87$ and 1.04, respectively) than in the control group $\left(M_{6}\right.$ months $=-.35$ and $-1.41, \mathrm{SD}_{6 \text { months }}=1.02$ and $1.05 ; M_{9 \text { months }}$ $=.43$ and $-.09, \mathrm{SD}_{9 \text { months }}=.96$ and .87 , respectively). For self-soothing, the opposite trend could be observed; that is, this behavior increased in the intervention group $\left(M_{6 \text { months }}=-1.77, \mathrm{SD}_{6}\right.$ months $=1.32$; $M_{9 \text { months }}=1.13, \mathrm{SD}_{9 \text { months }}=.73$ ), but it de- creased slightly in the control group over the two time points $\left(M_{6}\right.$ months $=.23, \mathrm{SD}_{6}$ months $\left.=.72 ; M_{9 \text { months }}=.17, \mathrm{SD}_{9 \text { months }}=.91\right)$.

Differences were predicted that favored intervention groups over the control groups on the following aspects of infant interactive behavior: more positive social behavior, less fussing and crying, and more exploration. The most consistent finding was that on posttreatment observations intervention infants were more sociable, more able to soothe themselves, and explored more compared to control group infants.

\section{Effect of Intervention on Infant Exploratory Behavior}

A major purpose of observing the infant's exploratory behavior was to examine changes in the quality of this behavior after intervention. To assess the effectiveness of the intervention, a 2 (pretest: yes vs. no) $\times$ 2 (intervention vs. control) MANOVA was conducted on the exploratory composites. This analysis revealed significant multivariate intervention and pretest effects, $F(4,93)$ $=5.26, p \leq .001, F(4,93)=3.21, p<.025$, respectively. No significant intervention $x$ pretest interaction was obtained. Univariate ANOVAs indicated that intervention infants showed significantly more sophisticated exploration $(M=.67, \mathrm{SD}=1.61), F(1,96)=$ $12.64, p=.001$, and less mouthing $(M=$ $-.31, \mathrm{SD}=1.42), F(1,96)=4.61, p<.05$, when compared to control group infants $(M$ $=-.67$ and $.31, \mathrm{SD}=2.08$ and 1.44 , respectively). No significant differences were found for either tempo of exploration or nonspecific manipulation. The effect for pretest was significant for sophisticated exploration, $F(1,96)=7.66, p<.01$, and nonspecific manipulation, $F(1,96)=5.04, p<.05$. Post hoc comparisons revealed that infants who were pretested received higher mean factor scores on sophisticated manipulation ( $M=$ $1.45, \mathrm{SD}=1.69$ ) than did infants who did not receive a pretest $(M=-.12, \mathrm{SD}=1.53)$. The opposite was found for nonspecific manipulation. In this case, infants who did not receive a pretest had higher scores $(M=.33$, $\mathrm{SD}=1.21)$ than pretested infants $(M=.13$, $\mathrm{SD}=1.47$ ).

A repeated-measures MANOVA on the pretested groups' sophisticated exploration, tempo of exploration, nonspecific manipulation, and mouthing revealed a significant multivariate main effect of intervention, $F(4$, $45)=5.80, p \leq .001$, and a multivariate interaction effect of intervention $\times$ time, $F(4$, $45)=6.10, p \leq .001$. There was no signifi- 
TABLE 4

INTERCORRELATIONS BETWEEN INTERACTIVE AND FREE-PLAY

MEASURES OF EXPLORATION

\begin{tabular}{|c|c|}
\hline Free Play & $\begin{array}{c}\text { Exploration } \\
\text { during Interaction }\end{array}$ \\
\hline $\begin{array}{l}\text { Sophisticated exploration } \\
\text { Tempo of exploration } \\
\text { Nonspecific manipulation } \\
\text { Mouthing }\end{array}$ & $\begin{array}{c}.28^{*} \\
-.01 \\
.09 \\
-.24^{*}\end{array}$ \\
\hline
\end{tabular}

$* p<.05$.

cant main effect of time. Univariate tests indicated that the interaction effect was significant for sophisticated exploration, $F(1$, $48)=16.25, p<.001$, with an increase in this kind of exploratory behavior in infants in the intervention group over time ( $M_{6}$ months $=-.77, \mathrm{SD}_{6 \text { months }}=2.44 ; M_{9 \text { months }}=1.45$, $\mathrm{SD}_{9 \text { months }}=1.69$ ), while in control group infants rates of sophisticated exploration decreased over time $\left(M_{6}\right.$ months $=.55, \mathrm{SD}_{6 \text { months }}$ $=2.57 ; M_{9 \text { months }}=-.42, \mathrm{SD}_{9 \text { months }}=2.41$ ). Nonspecific manipulation was also significant, $F(1,48)=5.49, p<.025$, indicating a decrease over time in rates of this behavior in intervention infants $\left(M_{6}\right.$ months $=1.02$, $\mathrm{SD}_{6 \text { months }}=1.08 ; M_{9 \text { months }}=.13, \mathrm{SD}_{9 \text { months }}$ $=1.47$ ), and an increase over time in the control infants $\left(M_{6 \text { months }}=-1.43, \mathrm{SD}_{6 \text { months }}\right.$ $\left.=2.55 ; M_{9 \text { months }}=-.84, \mathrm{SD}_{9 \text { months }}=1.77\right)$. Finally, mouthing proved to be significant, $F(1,48)=7.57, p<.01$, that is, over time it decreased in infants from the intervention group $\left(M_{6 \text { months }}=.40, \mathrm{SD}_{6 \text { months }}=1.55\right.$; $M_{9 \text { months }}=-.25, \mathrm{SD}_{9 \text { months }}=1.57$ ) and increased in infants from the control group $\left(M_{6 \text { months }}=-.50, \mathrm{SD}_{6 \text { months }}=1.60 ; M_{9 \text { months }}\right.$ $=.26, \mathrm{SD}_{9 \text { months }}=1.45$ ).

Pearson product-moment correlations were used to determine whether exploration observed during mother-infant interaction was related to quality of exploration assessed during free play. Quantity of exploration observed during mother-child interaction and sophisticated exploration in free play are significantly related, $r=.28, p<$ .01 (see Table 4). In addition, high rates of exploration during interaction are related to low rates of mouthing during free play, $r=$ $-.24, p<.05$. Although the correlations are significant, they are not high. It should be kept in mind, however, that the exploratory data collected during mother-child interaction provided information about the quantity of exploration, while the measure of free play was a qualitative measure. That quality of exploration requires a certain amount of quantity of exploration is clearly reflected in the significant correlations obtained.

Results from the analysis of the data gathered during the free play assessment of exploratory competence provide additional support for the conclusion that the intervention was effective in enhancing the quality of infant exploratory behavior. While the control infants were significantly more likely to engage in the least cognitively sophisticated kinds of play, the intervention infants engaged in functional play significantly more frequently.

\section{Changes in Reported Life Stress}

An ANOVA with repeated measures for life stress between infant age 6 and 9 months shows no significant intervention effect, a significant effect for time, $F(1,48)=28.6, p$ $<.001$, and no interaction. Reported life stress was high at entry $(M=11.04)$ and declined similarly for the pretested intervention and control groups to an overall sample mean of 7.26 .

\section{Delayed Posttreatment Effects}

The follow-up measure assessed was security of attachment at 12 months.

\section{Effect of Intervention on Quality of Attachment}

Log-linear analyses were conducted to examine the relation between infant-mother attachment and treatiment group. Because of the small number of subjects in the insecure resistant and insecure disorganized/ disoriented attachment categories, all three insecure categories were collapsed for subsequent data analysis into one insecure category and together were compared to the group of infants who were classified as securely attached. Separate two-way log-linear analyses of the interrelation of the pretested and no-pretest groups and attachment secu- 


\section{Child Development}

TABLE 5

Attachment Classifications at 12 Months FOR INFANTS IN EACH TrEatMENT Group

\begin{tabular}{|c|c|c|c|c|}
\hline & \multirow{2}{*}{$\frac{\text { SECURE }}{B}$} & \multicolumn{3}{|c|}{ INSECURE } \\
\hline & & A & $\mathrm{C}$ & $\mathrm{D}$ \\
\hline \multicolumn{5}{|l|}{ Pretest: } \\
\hline Intervention group ...... & 14 & 8 & 1 & 2 \\
\hline Control group & 6 & 13 & 4 & 2 \\
\hline \multicolumn{5}{|l|}{ No pretest: } \\
\hline Intervention group ...... & 17 & 4 & 2 & 2 \\
\hline 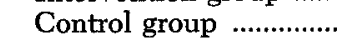 & 5 & 13 & 3 & 4 \\
\hline 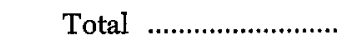 & 42 & 38 & 10 & 10 \\
\hline
\end{tabular}

Note. $-L^{2}$ for pretested groups $=5.45, p<.025 ; L^{2}$ for groups without pretest $=12.23, p<.001 ; L^{2}$ total $=$ 16.96, $p<.001$. Attachment classification: $\mathrm{B}=$ secure, $\mathrm{A}$ = insecure avoidant, $\mathrm{C}=$ insecure resistant, $\mathrm{D}=$ insecure disorganized/disoriented.

rity (secure vs. insecure) generated significant associations between group and attachment security, $L^{2}(1)=5.45$ and $12.23, p<$ .025 and $p<.001$, respectively. No pretreatment effects were found. Therefore, data were collapsed within the intervention and control groups. The result of the two-way log-linear analysis on this pooled data set was clear: An association was found between intervention group and attachment classification, $L^{2}(1)=16.96, p<.001$. Inspection of Table 5 indicates that $78 \%$ of control infants were classified in the insecure categories compared to $38 \%$ in the intervention groups. Only $28 \%$ of all control infants were assigned the traditional secure classification, compared to $62 \%$ of the intervention infants. Infants in the control groups were most likely to be classified as insecure avoidant (52\%) - not as insecure resistant, as would be expected from previous research with irritable infants.

\section{Discussion}

To date, two aspects in the study of the development of human attachment have been largely neglected despite increasing scientific endeavor in the field. Few investigators have directly addressed the problem of the influence of infant negative emotionality on the developing attachment relationship; the studies by Belsky, Fish, and Isabella (1991) and Crockenberg (1981) are notable exceptions. Second, few if any investigators have experimentally manipulated the aspect of behavior called maternal sensitivity, which in attachment theory is deemed crucial for the development of a se- cure attachment bond. The present study is unique in that infants were preselected on an aspect of temperament related to attachment security: negative emotionality. In addition, maternal sensitive responsiveness was experimentally manipulated in dyads with irritable infants, which are at risk for developing an anxious attachment relationship.

The findings indicate that the intervention was effective in enhancing maternal responsiveness, stimulation, visual attentiveness, and control. The fact that only one group difference in maternal behavior was evident before the treatment phase of the experiment, and that this difference was unfavorable for the intervention group, serves to buttress this conclusion. Infant behavior also changed after intervention. Intervention infants were more sociable, more able to soothe themselves, and engaged more frequently in cognitively sophisticated kinds of exploration than control infants. Hence, the intervention promoted substantial improvement in the quality of mother-infant interaction and the quality of infant exploration, parameters indicative of the quality of an attachment relationship.

A follow-up 3 months later revealed that significantly more intervention infants than control infants were securely attached, indicating that maternal sensitive responsiveness is causally related to infant attachment, at least in firstborn, irritable infants from lower-class families. In that they show significant intervention effects on attachment-related measures, our results are consistent with findings in high-risk samples by Lyons-Ruth, Zoll, Connell, and Odom (1987) and Lieberman, Weston, and Pawl (1991). Our findings differ from the results of Barnett, Blignault, Holmes, Payne, and Parker (1987) and Booth, Mitchell, Barnard, Spieker, and Magyary (1987), which did not show significant intervention effects on attachment classification. Like ours, the former studies involved populations with an increased risk of insecure infant attachment and focused on intervention on maternal sensitivity. In the latter studies, it is not clear whether the populations under study were at risk for developing an insecure attachment relationship and the intervention was not specifically geared toward enhancing sensitive maternal responsiveness. Both experimental differences may have contributed to the differences in effect.

The intervention model we employed 
in our research emphasizes maternal strengths rather than focusing on maternal inadequacies. We believe its strongest point is that it enhances the mother's feelings of effectiveness. Because mothers are instructed while they are interacting with their own infants, they themselves perform the actions that elicit the desirable infant behaviors. At the same time, they are convinced that the directions given are effective for their infant, something parents are not sure about when they are just given advice, either orally or in writing. In addition, by making mothers self-aware of their own growthpromoting parenting practices, we not only increased the incidence of such maternal behaviors but also influenced infant behavior.

Although we demonstrated that enhancing maternal sensitive responsiveness is beneficial for the development of a secure attachment relationship between mother and infant during the first year of life, a word of caution is in order. Sensitive responsiveness seems to refer to the current vogue for intervention in early infancy in which a "the more the better" philosophy may prevail. As part of the model for the ideal mother-infant relationship, a $100 \%$ level of maternal responsiveness could thus easily be adopted, with relationships falling below that level being regarded as suboptimal and intervention being geared to raising responsiveness to its maximum. However, such a goal would only be attainable in laboratory settings, where the two interactants are completely sheltered from all distractions and it is, therefore, very easy for the mother to attend to the infant virtually continuously. Mother-infant interactions in real-life settings such as the home present a rather different picture. And might there not even be some benefits in a certain amount of ignoring of the infant's signals-benefits such as self-reliance and learning to share the mother with others? Our conclusion, then, is that a fairly high level of responsiveness may well be beneficial, indeed essential, to the infant's development; it does not follow, however, that "the more the better" should be adopted as a guideline and that all intervention efforts should be directed toward maximum responsiveness. Such a conclusion seems to be in accord with results from other researchers (Belsky, Rovine, \& Taylor, 1984) whose findings show that secure infants experience neither especially high nor especially low, but actually intermediate, levels of reciprocal interaction.

The most significant theoretical finding of this work is its support for a relation between negative emotionality (assessed neonatally), quality of mother-infant interaction, and attachment classification in a group of irritable infants. Attachment theorists (Ainsworth, 1973; Waters, 1981) state that security is the functional goal of infant attachment behavior. An affective condition of security recognizes that the behavior required of mothers to foster feelings of security in their infants in most situations varies across infants (Thompson, 1986). The high rate of insecurity in the control groups may have been caused by the dual risk status of our sample. In addition to being preselected on irritability, the infants were raised in lower-class families where relatively high rates of insensitivity predominated (Mey, 1992). These aspects of maternal and infant behavior seem to influence the infant's understanding and interpretation of and adaptation to social events. The results of the experimental manipulation of maternal sensitive responsiveness in these dyads with irritable infants lends further support to this notion. Enhancing maternal responsiveness seems to foster the infant's sense of security, since it leads to an increase in exploratory behavior which is also of a higher quality compared to irritable infants receiving a lower level of maternal responsiveness. Moreover, our finding that the majority of control dyads are avoidantly attached directly challenges previous findings with irritable infants (Miyake, Chen, \& Campos, 1985) and the assumption of Chess and Thomas (1982) and Kagan (1984) and the conclusion drawn by Goldsmith and Alansky (1987) that such infants would be resistantly attached. The current data suggest a more complex process than a direct path between neonatal irritability and (Strange Situation) resistance. Neonatal irritability seems to be a general disposition that may predispose infants who are at risk for insecure relationships for other, contextual reasons toward insecurity but is not directly predictive of type of insecurity. Belsky and Isabella (1988) also found that as risks increased so did rates of insecurity.

Infant irritability seems to be an influential condition in the relationship between mother and infant in the first year of life. It makes it difficult for mothers to adjust their actions to the child's disposition. That mothers can be taught to do so is suggested by the increases in maternal responsiveness and in the amount and quality of infant exploratory behavior after an intervention geared to the characteristics of individual mother-infant 


\section{Child Development}

dyads. However, one must be wary of a new trend or relation, however intriguing, discovered in only one study. So far, very few studies with irritable infants have been conducted, and those that have been done do not present concordant results (Fish \& Crockenberg, 1981). Replications should address the question of how easily these techniques might be taught to others, since in this study all the intervention sessions were performed by the same person. In addition, the caveats associated with the implementation of only one kind of intervention must be reiterated in relation to our findings. Without the use of a comparison intervention group, the possibility cannot be ruled out that, in some way, the intervention dyads showed an improvement in their behavior simply because they received a great deal more attention than the control dyads. In order to control for such nonspecific placebo factors, future studies should include at least one other comparison intervention group so that the critical aspects of intervention may be identified more precisely than was possible from the present study. Further studies are needed to investigate the questions raised above and to elucidate the long-term effects of intervention through sustained follow-up of research populations who received an early intervention program. To uncover such possible long-term effects of our intervention, we are still collecting data on the sample we reported on in this article.

\section{References}

Aber, J. L., \& Baker, A. J. L. (1990). Security of attachment in toddlerhood. In M. T. Greenberg, D. Cicchetti, \& E. M. Cummings (Eds.), Attachment in the preschool years: Theory, research, and intervention (pp. 427-460). Chicago: University of Chicago Press.

Ainsworth, M. D. S. (1973). The development of infant-mother attachment. In B. M. Caldwell \& H. N. Ricciutti (Eds.), Review of child development research (Vol. 3, pp. 1-94). Chicago: University of Chicago Press.

Ainsworth, M. D. S., Blehar, M. C., Waters, E., \& Wall, S. (1978). Patterns of attachment: A psychological study of the Strange Situation. Hillsdale, NJ: ErIbaum.

Ainsworth, M. D. S., \& Wittig, B. A. (1969). Attachment and exploratory behavior of one-yearolds in a strange situation. In B. M. Foss (Ed.), Determinants of infant behavior (Vol. 4, pp. 113-136). London: Methuen.

Barnett, B., Blignault, I., Holmes, S., Payne, A., \& Parker, G. (1987). Quality of attachment in a sample of 1-year-old Australian children.
Journal of the American Academy of Child and Adolescent Psychiatry, 26, 303-307.

Bates, J. E., Maslin, C. A., \& Frankel, K. (1985). Attachment security, mother-child interaction, and temperament as predictors of behavior-problem ratings at age three years. In I. Bretherton \& E. Waters (Eds.), Growing points of attachment theory and research (pp. 167-195). Monographs of the Society for Research in Child Development, 50(1-2, Serial No. 209).

Bates, J. E., Olson, S., Pettit, G., \& Bayles, K. (1982). Dimensions of individuality in the mother-infant relationship at six months of age. Child Development, 53, 446-461.

Bell, S. M., \& Ainsworth, M. D. S. (1972). Infant crying and maternal responsiveness. Child Development, 43, 1171-1190.

Belsky, J., Fish, M., \& Isabella, R. (1991). Continuity and discontinuity in infant negative and positive emotionality: Family antecedents and attachment consequences. Developmental Psychology, 27, 421-431.

Belsky, J., Garduque, L., \& Hrncir, E. (1984). Assessing performance, competence, and executive capacity in infant play: Relations to home environment and security of attachment. Developmental Psychology, 20, 406-417.

Belsky, J., Goode, M. K., \& Most, R. K. (1980). Maternal stimulation, and infant exploratory competence: Cross-sectional, correlational, and experimental analyses. Child Development, 51, 1163-1178.

Belsky, J., \& Isabella, R. (1988). Maternal, infant, and social-contextual determinants of attachment security. In J. Belsky \& T. Nezworski (Eds.), Clinical implications of attachment (pp. 41-94). Hillsdale, NJ: Erlbaum.

Belsky, J., \& Most, R. K. (1981). From exploration to play: A cross-sectional study of infant freeplay behavior. Developmental Psychology, 17, 630-639.

Belsky, J., Rovine, M., \& Taylor, D. G. (1984). The Pennsylvania infant and family development project: III. The origins of individual differences in infant-mother attachment: Maternal and infant contributions. Child Development, 55, 718-728.

Booth, C. L., Mitchell, S. K., Barnard, K. E., Spieker, S. J., \& Magyary, D. (1987, April). Evaluating intervention with multirisk mothers: Links between social skills improvements and child outcomes. Paper presented at the biennial meeting of the Society for Research in Child Development, Baltimore.

Brazelton, T. B. (1973). Neonatal behavioral assessment scale. Philadelphia: Lippincott.

Buss, A. H., \& Plomin, R. (1984). Temperament: Early developing personality traits. Hillsdale, NJ: Erlbaum. 
Campbell, S. (1979). Mother-infant interaction as a function of maternal ratings of temperament. Child Psychiatry and Human Development, 10, 67-76.

Caron, J., \& Miller, P. (1981, April). Effects of infant characteristics on caretaker responsiveness among the Gusii. Paper presented at the biennial meeting of the Society for Research in Child Development, Boston.

Chess, S., \& Thomas, A. (1982). Infant bonding: Mystique and reality. American Journal of Orthopsychiatry, 52, 213-222.

Crockenberg, S. B. (1981). Infant irritability, mother responsiveness, and social support influences on the security of infant-mother attachment. Child Development, 52, 857-865.

Crockenberg, S. B. (1986). Are temperamental differences in babies associated with predictable differences in caregiving? In J. V. Lerner \& R. M. Lerner (Eds.), New directions for child development: Temperament and social interaction during infancy and childhood (pp. 53-73). San Francisco: Jossey-Bass.

Crockenberg, S. B., \& Acredolo, C. (1983). Infant temperament ratings: A function of infants, or mothers, or both? Infant Behavior and Development, 6, 61-72.

Crockenberg, S. B., \& Smith, P. (1982). Antecedents of mother-infant interaction and infant irritability in the first three months of life. $I n$ fant Behavior and Development, 5, 105-119.

Egeland, B., Breitenbucher, M., Dodds, M., Pastor, D., \& Rosenberg, D. (1979). Life stress and scoring manual. Unpublished manuscript, University of Minnesota, Minneapolis.

Egeland, B., \& Farber, E. A. (1982). Antecedents of infant-mother attachment relationships in economically disadvantaged families. Unpublished manuscript, University of Minnesota, Minneapolis.

Eigeland, B., \& Farber, E. A. (1984). Infant-mother attachment: Factors related to its development and changes over time. Child Development, 55, 753-771.

E'rickson, M. F., \& Farber, E. A. (1983, April). Infancy to preschool: Continuity of adaptation in high-risk children. Paper presented at the biennial meeting of the Society for Research in Child Development, Detroit.

Erickson, M. F., Sroufe, L. A., \& Egeland, B. (1985). The relationship between quality of attachment and behavior problems in preschool in a high-risk sample. In I. Bretherton \& E. Waters (Eds.), Growing points of attachment theory and research (pp. 147-166). Monographs of the Society for Research in Child Development, 50(1-2, Serial No. 209).

Field, T. (1982). Interaction coaching for high-risk infants and their parents. In H. A. Moss, R. Hess, \& C. Swift (Eds.), Early intervention programs for infants (pp. 5-24). New York: Haworth.

Fish, M., \& Crockenberg, S. (1981). Correlates and antecedents of nine-month infant behavior. Infant Behavior and Development, 4, 69-81.

Goldsmith, H. H., \& Alansky, J. A. (1987). Maternal and infant temperamental predictors of attachment: A meta-analytic review. Journal of Consulting and Clinical Psychology, 55, 805-816.

Grossmann, K., \& Grossmann, K. E. (1982, April). Maternal sensitivity to infants' signals during the first year as related to the year old's behavior in Ainsworth's Strange Situation in a sample of Northern German families. Paper presented at the International Conference on Infant Studies, Austin, TX.

Isabella, R. A., \& Belsky, J. (1991). Interactional synchrony and the origins of infant-mother attachment: A replication study. Child Development, 62, 373-384.

Isabella, R. A., Belsky, J., \& von Eye, A. (1989). The origins of infant-mother attachment: An examination of interactional synchrony during the infant's first year. Developmental Psychology, 25, 12-21.

Kagan, J. (1971). Change and continuity in infancy. New York: Wiley.

Kagan, J. (1984). The nature of the child. New York: Basic Books.

Kaye, K. (1978). Discriminating among normal infants by multivariate analysis of Brazelton scores: Lumping and smoothing. In A. J. Sameroff (Ed.), Organization and stability of newborn behavior: A commentary on the Brazelton Neonatal Behavior Assessment Scale (pp. 60-80). Monographs of the Society for Research in Child Development, 43(5-6, Serial No. 177).

Kelly, P. (1976). The relation of infant's temperament and mother's psychopathology to interactions in early infancy. In K. F. Riegel \& J. A. Meacham (Eds.), The developing individual in a changing world (Vol. 2, pp. 23-34). Chicago: Aldine.

Klein, P. (1984). The relation of Israeli mothers toward infants in relation to infants' perceived temperament. Child Development, 55, 1212-1218.

Koot, J. M. (1988). Relaties tussen sensitiviteit van moeders, de competentie van het kind en gehechtheid: Observatie aan een instructietaak [Relationships between maternal sensitivity, child competence, and attachment: $\mathrm{Ob}$ servation in an instructional situation]. In J. R. M. Gerris \& J. van Acker (Eds.), Gezinsrelaties onderzocht (pp. 53-63). Amsterdam: Swets \& Zeitlinger.

Lee, C., \& Bates, J. E. (1985). Mother-child inter- 


\section{Child Development}

action at age two years and perceived difficult temperament. Child Development, 56, 1314-1325.

Lewis, M., Feiring, C., McGuffog, C., \& Jaskir, J. (1984). Predicting psychopathology in sixyear-olds from early social relations. Child Development, 55, 123-136.

Lieberman, A. F., \& PawI, J. H. (1990). Disorders of attachment and secure base behavior in the second year of life. In M. T. Greenberg, D. Cicchetti, \& E. M. Cummings (Eds.), Attachment in the preschool years: Theory, research, and intervention (pp. 375-397). Chicago: University of Chicago Press.

Lieberman, A. F., Weston, D. R., \& Pawl, J. H. (1991). Preventive intervention and outcome with anxiously attached dyads. Child Development, 62, 199-209.

Linn, P., \& Horowitz, F. (1983). The relationship between infant individual differences and mother-infant interaction during the neonatal period. Infant Behavior and Development, 6 , 415-427.

Londerville, S., \& Main, M. (1981). Security of attachment, compliance, and maternal training methods in the second year of life. Developmental Psychology, 17, 289-299.

Lyons-Ruth, K., Zoll, D., Connell, D. B., \& Odom, R. (1987, April). Maternal depression as mediator of the effects of home-based intervention services. Paper presented at the biennial meeting of the Society for Research in Child Development, Baltimore.

Maccoby, E. E., \& Feldman, S. S. (1972). Motherattachment and stranger-reactions in the third year of life. Monographs of the Society for Research in Child Development, 37(1, Serial No. 146).

Main, M. (1973). Play, exploration and competence as related to child-adult attachment. Unpublished doctoral dissertation, Johns Hopkins University, Baltimore.

Main, M., \& Solomon, J. (1990). Procedures for identifying infants as disorganized/disoriented during the Ainsworth Strange Situation. In M. T. Greenberg, D. Cicchetti, \& E. M. Cummings (Eds.), Attachment in the preschool years: Theory, research, and intervention (pp. 121-160). Chicago: University of Chicago Press.

Maslin, C. A., \& Bates, J. E. (1982, May). Anxious attachment as a predictor of disharmony in the mother-toddler relationship. Paper presented at the International Conference on Infant Studies, Austin, TX.

Matas, L., Arend, R. A., \& Sroufe, L. A. (1978). Continuity of adaptation in the second year: The relationship between quality of attachment and later competence. Child Development, 49, 547-556.
McCall, R. B. (1974). Exploratory manipulation and play in the human infant. Monographs of the Society for Research in Child Development, 39(2, Serial No. 155).

Mey, J. Th. H. (1992). Sociale ondersteuning, gehechtheidskwaliteit en vroegkinderlijke competentie-ontwikkeling [Social support, quality of attachment, and the early development of competence]. Unpublished doctoral dissertation, University of Nijmegen.

Milliones, J. (1978). Relationship between perceived child temperament and maternal behavior. Child Development, 49, 1255-1257.

Miyake, K., Chen, S., \& Campos, J. J. (1985). Infant temperament, mother's mode of interaction, and attachment in Japan: An interim report. In I. Bretherton \& E. Waters (Eds.), Growing points of attachment theory and research (pp. 276-297). Monographs of the Society for Research in Child Development, 50(1-2, Serial No. 209).

Netherlands Central Bureau of Statistics. (1971). Systematische classificaties: Deel 2, Beroepenclassificaties [Systematic classifications: Vol. 2, Classification of professions]. Voorburg: Netherlands Central Bureau of Statistics.

Osofsky, J. D. (1976). Neonatal characteristics and mother-infant interaction in two observational situations. Child Development, 47, 1138-1147.

Osofsky, J. D., \& Danzger, B. (1974). Relationships between neonatal characteristics and mother-infant interaction. Developmental Psychology, 10, 124-130.

Peters-Martin, P., \& Wachs, T. D. (1984). A longitudinal study of temperament and its correlates in the first 12 months. Infant Behavior and Development, 7, 285-298.

Pettit, G., \& Bates, J. (1984). Continuity of individual differences in the mother-infant relationship from 6 to 13 months. Child Development, 55, 729-739.

Power, T. G., Chapieski, M. L., \& McGrath, M. P. (1985). Assessment of individual differences in infant exploration and play. Developmental Psychology, 21, 974-981.

Rothbart, M. K., \& Derryberry, D. (1981). Development of individual differences in temperament. In M. E. Lamb \& A. L. Brown (Eds.), Advances in developmental psychology (Vol. 1, pp. 37-86). Hillsdale, NJ: Erlbaum.

Smith, P. B., \& Pederson, D. R. (1988). Maternal sensitivity and patterns of infant-mother attachment. Child Development, 59, 10971101.

Solomon, R. L,, \& Lessac, M. S. (1968). A control group design for experimental studies of developmental processes. Psychological Bulletin, 70, 145-150. 
Sorce, J. F., \& Emde, R. N. (1981). Mother's presence is not enough: Effects of emotional availability on infant exploration. Developmental Psychology, 17, 737-745.

Sroufe, L. A. (1983). Infant-caregiver attachment and adaptation in the preschool: The roots of competence and maladaptation. In M. Perlmutter (Ed.), Minnesota symposium in child development (Vol. 16, pp. 41-81). Hillsdale, NJ: Erlbaum.

Sroufe, L. A., Fox, N. E., \& Pancake, V. R. (1983). Attachment and dependency in developmental perspective. Child Development, 54, 1335-1354.

Stern, D. (1971). A micro-analysis of mother-infant interaction: Behavior regulating social contact between a mother and her $3 \frac{11}{2}$-month-old twins. Journal of the American Academy of Child Psychiatry, 10, 501-517.

Thompson, R. A. (1986). Temperament, emotionality, and infant cognition. In J. V. Lemer \& R. M. Lerner (Eds.), New directions for child development: Temperament and social interaction during infancy and childhood (pp. 3552). San Francisco: Jossey-Bass.

Thompson, R. A., \& Lamb, M. E. (1983). Security of attachment and stranger sociability in infancy. Developmental Psychology, 19, 184191.

van den Boom, D. C. (1988). Neonatal irritability and the development of attachment: Observation and intervention. Unpublished doctoral dissertation, University of Leiden. van den Boom, D. C. (1989). Neonatal irritability and the development of attachment. In G. A. Kohnstamm, J. E. Bates, \& M. K. Rothbart (Eds.), Temperament in childhood (pp. 299318). New York: Wiley.

van den Boom, D. C. (1991). The influence of infant irritability on the development of the mother-infant relationship in the first six months of life. In J. K. Nugent, B. M. Lester, \& T. B. Brazelton (Eds.), The cultural context of infancy (Vol. 2, pp. 63-89). Norwood, NJ: Ablex.

Vaughn, B. E., Stevenson-Hinde, J., Waters, E., Kotsaftis, A., Lefever, G. B., Shouldice, A., Trudel, M., \& Belsky, J. (1992). Attachment security and temperament in infancy and early childhood: Some conceptual clarifications. $D e-$ velopmental Psychology, 28, 463-473.

Waters, E. (1981). Traits, behavioral systems, and relationships: Three models of infant-adult attachment. In K. Immelman, G. W. Barlow, L. Petrinovich, \& M. Main (Eds.), Behavioral development (pp. 621-650). Cambridge: Cambridge University Press.

Watson, J. S. (1979). Perception of contingency as a determinant of social responsiveness. In $E$. B. Thoman (Ed.), The origins of the infant's social responsiveness (pp. 33-64). Hillsdale, NJ: Erlbaum.

Wenckstern, S., Weizmann, F., \& Leenaars, A. A. (1984). Temperament and tempo of play in eight-month-old infants. Child Development, 55, 1195-1199. 
This document is a scanned copy of a printed document. No warranty is given about the accuracy of the copy. Users should refer to the original published version of the material. 